\title{
EFFECTS OF DYNAMIC COMPRESSION ON CELLS IN TISSUE ENGINEERING OF MANDIBULAR CONDYLAR CARTILAGE
}

\author{
S. Cortez (1), A. Completo (2), J.L. Alves (1) \\ 1. CMEMS - University of Minho, scortez@dem.uminho.pt; \\ 2. TEMA - University of Aveiro, completo@ua.pt;
}

\section{Introduction}

Osteoarthritis, caused by degeneration of the mandibular condyle cartilage, affects human health and limited mobility of the temporomandibular joint for many patients [1]. Due to the high prevalence of this condition, there is a strong motivation to improve the cell culture techniques in the development of a new implantable tissue [2]. Numerical modelling by finite element methods can be used to guide these experimental tests and to understand the intrinsic phenomena during the culture, producing engineered cartilage with optimized biomechanical properties [3].

Bioreactors can provide a suitable environment for the transport of nutrients and the good mechanical stimuli to the cells [4]. The response of chondrocytes to mechanical stimuli affects the remodelling of cartilage solid matrix [5].

This study aims to determine how the dynamic compressive loading can affects the metabolism of the chondrocytes in tissue engineering of mandibular condylar cartilage.

\section{Methodology}

In this study, a mathematical model was developed to simulate the cell growth in a $3 \mathrm{D}$ porous scaffold to produce the mandibular condylar cartilage.

This numerical approach involves the transport and the absorption of solutes, such as glucose and oxygen, the lactate production and the $\mathrm{pH}$ effects within the construct. The model was developed taking into account the association between cell growth and the shear stresses developed by the fluid flow within the scaffold. The modified Monod-Contois model with a modulation function was implemented, considering the beneficial effect of shear stress on the tissue growth [6]. The simulation uses a quarter of a non-woven PGA disc-shape scaffold with a $5 \mathrm{~mm}$ diameter and $2 \mathrm{~mm}$ of thickness. Free-swelling conditions and mechanical stimulations $(10 \%$ compressive strain at a frequency of $1 \mathrm{~Hz}$ ) were compared.

The simulation predicts the influence of the solutes diffusion and the local shear stress in the cell proliferation within the scaffold over a culture period of 14 days.

\section{Results and Discussion}

The solute concentrations and cell content showed good agreement with experimental data. The results indicated that the presence of a dynamic compression loading and, therefore, local shear stresses, improves the cell growth inside the scaffold.

\section{Conclusion}

This mathematical structure allows to investigate how chondrocytes respond to different stimulation, simulating the culture environment in a bioreactor. This study may also be used to understand the intrinsic events that occur during the culture process, helping the improvement of the scaffold design and its culture method.

\section{References}

[1] Kuroda S., et al, Osteoarthritis and Cartilage, 17(11): 1408-1415, 2009.

[2] Wang L., et al, Tissue Engineering, 13(8):19551971, 2007.

[3] Sengers B.G., et al, J Biomech Eng, 126(1): 8291, 2004.

[4] Martin I., et al, Trends in Biotechnology, 22(2): 80-86, 2004.

[5] Lane Smith R., et al., Biorheology, 37(1): 95$107,2000$.

[6] Nava M., et al, Biomech Model Mechanobiol, 12(6): 1169-1179, 2013.

\section{Acknowledgements}

The first author is grateful to FCT (Fundação para a Ciência e Tecnologia) for the $\mathrm{PhD}$ grant (SFRH/BD/87933/2012). This work is supported by FCT with the reference projects UID/EEA/04436/2013, PEstC/EME/UI0481/2013, FCOMP-01-0124-FEDER015191, and by FEDER funds through the COMPETE 2020 - Programa Operacional Competitividade $e$ Internacionalização (POCI) with the reference projects POCI-01-0145-FEDER-006941 and COMPETE 2020 PTDC/ EMSTEC/ 3263/ 2014. 